\title{
Computer aspect of interdisciplinary research in philosophy of education and computer science
}

\author{
Julia Petrova ${ }^{1}$ and Olga Vasichkina ${ }^{* 2}$ \\ ${ }^{1}$ Faculty of Linguistics and Journalism, FSBEHE RSUE, B.Sadovaya str., 69, Rostov-on-Don, 344001, Russia, julia- \\ pp@yandex.ru \\ ${ }^{2}$ Faculty of Linguistics and Journalism, FSBEHE RSUE, B.Sadovaya str., 69, Rostov-on-Don, 344001, Russia, \\ ms.vasichkina@mail.ru
}

\begin{abstract}
A large-scale global study of events both within and between disciplines provides strong evidence that leading thinkers have begun to introduce new ways of thinking to the point that most academic disciplines have undergone major paradigm changes throughout the twentieth century, according to Guidley. Increasingly, over the past forty years, we can see significant changes, if not in all, then in the main scientific disciplines. New ways of thinking have appeared in almost all disciplines. With the help of interdisciplinary approaches, a movement has emerged to integrate knowledge, moving beyond the fragmentation of knowledge related to disciplinary specialization. Computer technologies and computer concepts have penetrated almost all areas of academic research. These events can be considered as the implementation of new ways of thinking and new models of knowledge, respectively, and may be edges of the evolution of consciousness, in which computer technologies occupy a significant place. Education and communication in the age of globalization and computerization are an obvious necessity for the continued existence of society.
\end{abstract}

\section{Introduction}

As scientific knowledge develops across a wide range of disciplines, scientists are increasingly aware of the need to connect disciplinary areas to get fuller answers to critical questions and simplify the application of knowledge in a particular field. Nowadays there is also a growing emphasis on promoting interdisciplinary research and supporting it through a number of specific proposals. Integrative research concepts such as interdisciplinarity and transdisciplinarity are becoming more and more widely spread in research. Despite the widespread opinion that interdisciplinary cooperation is useful, there is not enough research on the problem of the philosophy of education and the philosophy of computer science, and the impact of computer telecommunications on education. According to J. Nash, the main problem in interdisciplinary research extends to "intrapersonal, interpersonal system levels"[1]. In parallel with the problems of interdisciplinary research, we suggest changes in cooperation. For the purposes of our study, collaboration is defined as "working together" with other parties to determine the achievement of mutually agreed goals [2].

\section{Problem Statement}

Modern science is not widely taught in educational institutions because it is considered to be complex, expensive and / or esoteric. Enlarging the ways to provide access to new intellectual tools of modern science (scientific papers, articles, monographs, research, etc.) significantly helps increase the international competitiveness of not only institutions, but also countries.

Institutions are usually organized in terms of disciplines (such as philosophy) or practices (such as education). Disciplines reveal some phenomenon in the world and make it a subject of study while practice is an integral part of the process. Thus, educational practice, for example, is part of the pedagogical process, in which higher education, as in the case of critical thinking, requires creative thinking and is an ideal place for practice, skill development and the formation of a moral personality.

\section{Research Questions}

Researchers of the philosophy of education, which is considered a branch of practical philosophy, address both the internal discipline of philosophy and educational practice, as well as developmental psychology, cognitive science in general, and other relevant disciplines [3]. The philosophy of education is the field of philosophy that deals with philosophical questions concerning the nature, goals, and problems of education. "...to call the philosophy of education a special branch of philosophy does not mean, however,

\footnotetext{
* Corresponding author: ms.vasichkina@mail.ru
} 
that it is a separate branch in the sense that it can exist separately from the established branches of philosophy. ... It would be more appropriate to perceive the philosophy of education as using branches of philosophy and combining them in ways that are relevant to educational issues" [4].

The theory of constructivism in education assumes that people create their own understanding and knowledge of the world through communication, experience, and reflection on the created experience. We use the term "collaboration" interchangeably with terms such as communication, collaboration, mutual planning and integration, and assistance [5]. While most of the phenomena and problems currently being investigated are too complex to be fully described in the context of a single field of philosophy - the philosophy of education, or the philosophy of computer science, interdisciplinary research has the potential to improve communication and accelerate the implementation of discoveries in practice.

\section{Purpose of the Study}

The philosophy of education, as a branch of applied or practical philosophy, studies the nature and goals of education, as well as philosophical problems that arise in the theory and practice of education. This field of philosophy, since it is the practice of all human societies, its social and individual manifestations are diverse, and its influence is so profound that the broad nature of this problem affects questions of ethics, social and political philosophy, epistemology, metaphysics, philosophy of thought, language, reasoning, value and moral education, teaching and learning [6].

The term "philosophy of computer science" is not as well known as "philosophy of education". One of the original characteristics of the term "philosophy of computer science" we see in the work of Timothy R. Colburn "Philosophy and Computer Science (Explorations in Philosophy)" (2000), in which the scientist traces the philosophy of all computer sciences. The author claims that the philosophy of computer science is a "special discipline" in the same sense as the philosophy of education [7]. It certainly differs to a certain extent from the philosophy of artificial intelligence, philosophy of information, and philosophy of mind, being a separate research area of the philosophy of science, but as a branch of philosophy it also deals with the problems of specific academic disciplines, which usually include ontological, epistemological, and methodological problems, as well as questions about logic, ethics, and semantics, in which we can trace the philosophy of all computer sciences.

Computer technologies and computer concepts have penetrated almost all areas of academic research. This interdisciplinary specialization makes it possible to combine the study of computer science with other academic disciplines, combine the study of computer science with traditional academic disciplines such as physics, chemistry, sociology or biology, and/or with new fields that include a significant computational component, such as bioinformatics, cognitive science and digital art. [8].

\section{Research Methods}

Combining the study of computer technology and computer concepts, for example, with cognitive science, makes it possible to consider such problems as the intelligent behavior of computers and robots, to understand the human brain and human intelligence using computational models, and predict some social and ethical consequences of the intelligent machines introduction. Interdisciplinary research in this field combines philosophy with relevant courses in computer science and mathematics.

The value of interdisciplinary research is in promoting the areas of study and accelerating scientific discoveries. And since the ideas researched often exceed the limits of a single discipline or program, integration of research by means of the interdisciplinary approach prepares a workforce that solves scientific problems in an innovative way. Technology has always been at the forefront of human education. From the times of figures carved on the stone walls to the present day, when most of the students are equipped with several portable technological devices, technology continues to raise educational potentialities to a new level. When you look at where educational methods and tools have come from, and where they will take us in the future, the importance of technology in education and research becomes now more obvious than ever before. However different the history of computers in these fields may be characterized, it is clear that innovators in this field have created the most provocative and stimulating ideas in the history of interdisciplinary research.

\section{Findings}

The age of computers in education since the second half of the 20th century [9] has improved the quality of education in many ways. For example, computer text processing programs have made it easier to correct spelling errors, grammatical errors, and punctuation marks. Some of the latest text editors can insert text quotes into student's research papers. Similarly, the software can correct errors and check the plagiarism of the work under study. Therefore, the benefits that come with text-based computer writing software outweigh the negative impact on students' writing literacy. The Internet has opened the door to information, knowledge, and educational resources, and has expanded learning opportunities both inside and outside the educational institutions [10].

Teachers use online materials to prepare lessons, and students use them to expand their range of learning and research. Information and communication technologies and high-speed computers have revolutionized the concept of information processing, provided an environment for alternative learning and research. Computers being in use since the beginning of the last century are changing the way we learn, become a critical 
addition to educational perception, and thus open up more learning opportunities [11].

Currently the usage of Information and communication technologies in education brought a new era, characterized by expanded access to education, improved quality of education and by strengthening the relevance of education as a digital workplace. The Internet has changed the way and the image of education and has become an incentive to optimize teaching methods. Thanks to easy access to the Internet, distant learning is becoming increasingly popular.

The growing demand for courses and programs with more profound specialization forces the universities to differentiate their offers in the educational sphere. Currently, educational computer literacy in Russia is experiencing a new explosion caused by the pandemic of the century. The most important are all kinds of interrelated competencies needed to improve people's interaction with information, both for educational and scientific purposes.

The theory of constructivism in education assumes that people create their own understanding and knowledge of the world through experience and reflection based on the created experience. We use the term "collaboration" interchangeably with such terms as communication, collaboration, mutual planning, and integration assistance [12]. While most of the phenomena and problems currently being investigated are too complex to be fully described in the context of a single field of philosophy - the philosophy of education, or the philosophy of computer science, interdisciplinary research has the potential to improve communication and accelerate the implementation of discoveries in practice. For the purposes of this study, "collaboration" is understood as working together with other parties to determine the achievement of mutually agreed goals [2].

Different countries of the world have their own intellectual traditions and their own ways of institutionalizing philosophy in the academic universe. Society not only continues to exist through cooperation, transmission, and communication, but one can say that it exists within them. There is more than just a verbal connection between the words "community" and "communication". People live in society because they have something in common, and communication is an "example of a speech event" [13], a way in which common features, values, and interests are found and revealed. With the help of technology, opportunities for communication and collaboration expanded significantly. Traditionally, classrooms were relatively isolated, with collaboration being limited to other students in the group or in the building. The main goal in the communication process is to understand people, that is, to understand the context [14]. "...examples of multicultural and cross-cultural communication are becoming a common form of communication for many people in their daily lives" [15]. Today, computer telecommunications provide such forms of communication and collaboration that have never been dreamed about before. For example, students can read publications of scientists in blogs; send questions to scientists by email; participate in video conferences; share what they are studying with students in other classrooms, cities and countries who are investigating a similar problem; work together on group projects; use virtual scientific laboratories to conduct scientific experiments, etc. Thus, students of the 21 st century have a great opportunity to form communities of researchers who share "believes, aspirations, knowledge, understanding, and common sense..." [16].

\section{Conclusion}

Education and communication in the age of globalization and computerization are an obvious necessity for the continued existence of society. It may seem that we are somewhat fixed on the truism. Though, the justification is that this emphasis is a means of distracting us from the excessively scholastic and formal understanding of education. One of the tasks of education is the formation of a moral personality, but this is only one task, and it is relatively perfunctory in comparison with the others. Only by recognizing the need for more fundamental and permanent teaching methods we can make sure that scholastic methods are placed in their true context. W. Jacob notes that nowadays higher educational institutions can no longer train graduates to solve all current and emerging problems basing on a single disciplinary source. Interdisciplinary research approaches are the most essential foundation for best meeting the dynamic needs of today's students of higher educational institutions [17].

The exclusivity and uniqueness of the education development in the socio-cultural space of various countries and regions remain a determining factor in the formation of national characteristics that reflect the ideas of individual peoples about national and historical values and determine the fundamental nature of national education. Simon G. notes that advances in science and information processing technologies have changed the meaning of the verb "to know". If it used to mean "store information in your memory", now this means access to information, the ability to identify it, extract it, and use it [18].

Global transformations that have affected humanity have become a criterion for the unification of education, determining international trends in its development. This new approach to education results from the influence of complex and ambiguous processes in the development of society, changes both in the nature of relations between people and the improvement of technologies, the evolution of the way of communication. "The indisputable relevance of education issues is related to the current trends in increasing the importance of the educational sphere, the formation of teaching methods that meet the realities of our days, which consist both in the transfer of knowledge and in its preservation" [19]

\section{References}

1. J.M. Nash, Am J Prevent Med. 35( 2), 133-140 (2008) 
2. N. Wells, R. Johnson \& S. Salyer, The international journal of advanced nursing practice 12(4), 161-166 (1998)

3. H. Siegel, The Oxford Handbook of Philosophy of Education. Retrieved from (2009), URL:https://www.oxfordhandbooks.com/view/10.1 093/oxfordhb/9780195312881.001.0001/oxfordhb9780195312881-e-001 (date of access: 16.03.21).

4. I. Scheffler, Reason and Teaching (Hackett Publishing, 1989)

5. D. Drotar, Developmental \& Behavioral Pediatrics, 23(3), 175-180 (2002)

6. T. Husén, \& N. Postlethwaite, Philosophy of Education 7, 3859-3877 (1985)

7. T.R. Colburn, Philosophy and computer science (Armonk, Routledge, 2000)

8. Van Wormer, R., Lindquist, W. Robiner S. Finkelstein, Dimensions of critical care nursing: DCCN. 31(3), 202-210 (2012)

9. Informational Technology and its Impact on American Education. Office of Technology Assessment, U.S. Congress, Washington, DC (1982),

URL: https://www.princeton.edu/ ota/disk3/1982/8216/82 16.PDF 001 (date of access: 16.03.21).

10. H.L. Lim, Innovative Methods and Technologies for Electronic Discourse Analysis (IGI Global, 2013)

11. Y. Petrova, \& L. Olifirenko, Humanities and socioeconomic sciences, 3 (112), 18-21 (2020)

12. D. Drotar, Developmental \& Behavioral Pediatrics, 23(3), 175-180 (2002)

13. Y.A. Petrova, Humanities and socio-economic sciences, 2 (87), 88-90. (2016).

14. E.E. Nesmeyanov, \& Yu.A. Petrova, SHS Web of Conferences: Trends in the Development of PsychoPedagogical Education in the Conditions of Transitional Society. 70 (2019)

15. M. Estaji, \& A. Rahimi, International Journal of Society, Culture \& Language (IJSCL), 6 (2), 1-18 (2020)

16. J. Dewey, Democracy and Education, EBook \#852/ 2015 ,

URL: https://www.gutenberg.org/files/852/852-h/852h.htm\#link2HCH0008 (date of access: 16.03.21).

17. W. Jacob, Palgrave Communications 1, 15001 (2015)

18. H.A. Simon, Designing Organizations for an Information -Rich World (Baltimore, MD: Johns Hopkins Press, 1971)

19. Collection of scientific papers. Theory and practice of teaching foreign languages in a non-linguistic university: traditions of innovation, prospects, (2014)

URL: http://elib.fa.ru/fbook/melnichuk.pdf/download/mel nichuk.pdf (date of access: 16.03.21). 